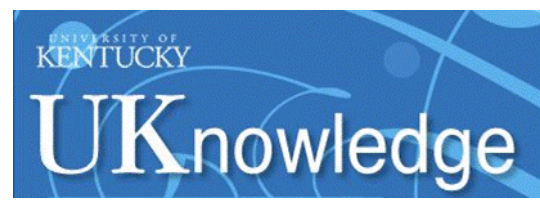

University of Kentucky

UKnowledge

8-7-2017

\title{
Polymer Nanoassemblies with Hydrophobic Pendant Groups in the Core Induce False Positive siRNA Transfection in Luciferase Reporter Assays
}

\author{
Steven Rheiner \\ University of Kentucky, Steven.rheiner@uky.edu \\ Derek Alexander Reichel \\ University of Kentucky, derek.a.reichel@gmail.com \\ Piotr G. Rychahou \\ University of Kentucky, piotr.rychahou@uky.edu \\ Tadahide Izumi \\ University of Kentucky, t.izumi@uky.edu
}

See next page for additional authors

Right click to open a feedback form in a new tab to let us know how this document benefits you. Follow this and additional works at: https://uknowledge.uky.edu/ps_facpub

Part of the Pharmacy and Pharmaceutical Sciences Commons 


\section{Polymer Nanoassemblies with Hydrophobic Pendant Groups in the Core Induce False Positive siRNA Transfection in Luciferase Reporter Assays}

\section{Digital Object Identifier (DOI)}

https://doi.org/10.1016/j.ijpharm.2017.06.056

\section{Notes/Citation Information}

Published in International Journal of Pharmaceutics, v. 528, issues 1-2, p. 536-546.

(C) 2017 Elsevier B.V. All rights reserved.

This manuscript version is made available under the CC-BY-NC-ND 4.0 license

https://creativecommons.org/licenses/by-nc-nd/4.0/.

The document available for download is the author's post-peer-review final draft of the article.

\section{Authors}

Steven Rheiner, Derek Alexander Reichel, Piotr G. Rychahou, Tadahide Izumi, Hsin-Sheng Yang, and Younsoo Bae 
Published in final edited form as:

Int J Pharm. 2017 August 07; 528(1-2): 536-546. doi:10.1016/j.ijpharm.2017.06.056.

\title{
Polymer Nanoassemblies with Hydrophobic Pendant Groups in the Core Induce False Positive siRNA Transfection in Luciferase Reporter Assays
}

\author{
Steven Rheiner ${ }^{\mathrm{a}}$, Derek Reichel ${ }^{\mathrm{a}}$, Piotr Rychahou ${ }^{\mathrm{b}, \mathrm{c}}$, Tadahide Izumi ${ }^{\mathrm{d}}$, Hsin-Sheng Yang ${ }^{\mathrm{b}, \mathrm{d}}$, \\ and Younsoo Bae ${ }^{a}{ }^{*}$ \\ aDepartment of Pharmaceutical Sciences, College of Pharmacy, University of Kentucky, 789 \\ South Limestone, Lexington, KY 40536, USA \\ bMarkey Cancer Center, University of Kentucky, 800 Rose Street, CC140, Lexington, KY 40536 \\ 'Department of Surgery, College of Medicine, University of Kentucky, 741 South Limestone, \\ Lexington, KY 40536, USA \\ ${ }^{\mathrm{d} D e p a r t m e n t}$ of Toxicology and Cancer Biology, College of Medicine, University of Kentucky, 1095 \\ V.A. Drive, Lexington, KY 40536
}

\section{Abstract}

\begin{abstract}
Poly(ethylene glycol)-conjugated polyethylenimine (PEG-PEI) is a widely studied cationic polymer used to develop non-viral vectors for siRNA therapy of genetic disorders including cancer. Cell lines stably expressing luciferase reporter protein typically evaluate the transfection efficacy of siRNA/PEG-PEI complexes, however recent findings revealed that PEG-PEI can reduce luciferase expression independent of siRNA. This study elucidates a cause of the false positive effect in luciferase assays by using polymer nanoassemblies (PNAs) made from PEG, PEI, poly-(L-lysine) (PLL), palmitate (PAL), and deoxycholate (DOC): PEG-PEI (2P), PEG-PEI-

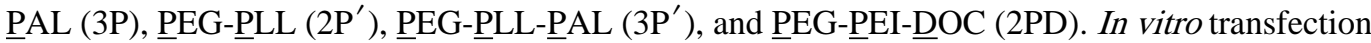
and western blot assays of luciferase using a colorectal cancer cell line expressing luciferase (HT29/LUC) concluded that $2 \mathrm{P}$ and $2 \mathrm{P}^{\prime}$ caused no luciferase expression reduction while hydrophobically modified PNAs induced a 35-50\% reduction (3P'<2PD $<3$ P). Although cell viability remained stagnant, $3 \mathrm{P}$ triggered cellular stress responses including increased membrane porosity and decreased ATP and cellular protein concentrations. Raman spectroscopy suggested that hydrophobic groups influence PNA conformation changes, which may have caused overubiquitination and degradation of luciferase in the cells. These results indicate that
\end{abstract}

\footnotetext{
"To whom correspondence should be addressed: Younsoo Bae, Ph.D., Department of Pharmaceutical Sciences, College of Pharmacy, University of Kentucky, 789 South Limestone, Lexington, KY 40536-0596, USA, Phone: +1-859-323-6649, Fax: +1-859-257-7564, younsoo.bae@uky.edu.

Chemical compounds studied in this article: Ethylene glycol (PubChem CID: 174); Polyethylenimine (PubChem SID: 24865591); Poly-1-lysine (PubChem SID: 24898886); Palmitic Acid (PubChem CID: 985); Deoxycholic Acid (PubChem CID: 222528)

Publisher's Disclaimer: This is a PDF file of an unedited manuscript that has been accepted for publication. As a service to our customers we are providing this early version of the manuscript. The manuscript will undergo copyediting, typesetting, and review of the resulting proof before it is published in its final citable form. Please note that during the production process errors may be discovered which could affect the content, and all legal disclaimers that apply to the journal pertain.
} 
hydrophobically modified PEG-PEI induces cellular distress causing over-ubiquitination of the luciferase protein, producing false positive siRNA transfection in the luciferase assay.

\section{Graphical abstract}
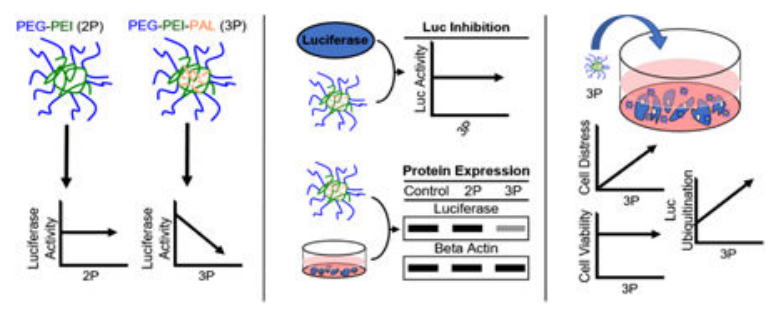

\section{Keywords}

Polymer nanoassemblies; gene delivery; siRNA; false transfection; luciferase reporter assays; polyethylenimine

\section{Introduction}

Small interfering RNA (siRNA) can suppress mutated genes generating proteins which are currently unable to be targeted by small molecule drugs and thus provide a new therapy for genetic diseases including cancer (Davis et al., 2010; Lee et al., 2016; Wittrup and Lieberman, 2015). However, siRNA often shows low transfection in vivo due to poor delivery efficiency (Kim and Rossi, 2007). To improve delivery of siRNA to target sites, polymer-based non-viral gene vectors have been developed, which include ionic complexes between anionic siRNA and cationic polyethyleneimine (PEI) (Pandey and Sawant, 2016; Patil and Panyam, 2009). siRNA/PEI complexes have achieved successful gene silencing in various human cells in vitro, but they are unstable in the body (Wightman et al., 2001). Polyethyleneglycol (PEG) is frequently used to stabilize siRNA/PEI complexes (Malek et al., 2008; Nelson et al., 2013). The hydrophilic PEG chains surrounding siRNA/PEI complexes can shield the particle charge and prevent protein adsorption. The siRNA/PEI complexes can be further modified with hydrophobic excipients and other additives for improving stability and fine-tuning release of siRNA (Zintchenko et al., 2008).

Based on this background, we developed siRNA delivery vectors by using polymer nanoassemblies (PNAs) made from PEG, PEI, and hydrophobic pendant groups such as palmitate (PAL) (Rheiner et al., 2015). PNAs are unimolecular assemblies of $30 \mathrm{~nm}$ diameter particles having cationic polymer backbone to which PEG and a hydrophobic moiety can be covalently conjugated. In previous studies, we reported that these PNAs enhanced siRNA transfection in a human colorectal cancer HT29 cell line as functions of PEG composition and PAL modification. These PNAs displayed siRNA transfection efficiency comparable to PEG-PEI formulations developed by other research groups (Fella et al., 2008; Liu et al., 2013) as well as commercially available transfection reagents such as RNAiMAX. However, we have recently observed that PEG-PEI alters siRNA transfection among product batches partially due to PEG compositions such as molecular weight, substitution rate, and PEI contaminants (Rheiner and Bae, 2016). PEG-PEI also appeared to 
substantially change siRNA transfection efficiency before and after conjugation of hydrophobic pendant groups, although the mechanism remained elusive (Rheiner et al., 2015). However, further study of the hydrophobic modification to PEG-PEI also revealed unexpectedly reduced luciferase expression in cells even in the absence of siRNA, called the false positive effect.

The false positive effect on siRNA transfection is troubling in evaluating and predicting in vivo performance of non-viral gene vectors made from PEG-PEI for future studies and clinical applications. Usually, protein reporter assays are used to evaluate the transfection efficiency of the siRNA/PEG-PEI complex, and luciferase is one of the reporter proteins that offer a quick method for measuring siRNA-mediated gene silencing in living cells (Auld et al., 2008; Bartlett and Davis, 2006; Helmfors et al., 2015). Luciferase protein activity is correlated to the amount of luciferase protein in the cell following siRNA transfection by measuring luminescence using luminogenic substrates (Choy et al., 2003). Luciferase has a short half-life in live cells, less than 3 hours (Thorne et al., 2010), which makes it ideal for determining long-term siRNA transfection efficiency. Any protein left within the cell after incubation with siRNA/PEG-PEI complexes would be produced after the siRNA has had a chance to take effect. However, this would not account for protein that has been denatured or had its expression reduced by other means. If PEG-PEI can interfere with the luciferase reporter assay this way, it would explain siRNA transfection efficiency varying among product batches.

Another possible reason for inconsistent siRNA transfection of PEG-PEI is the cellular stress responses triggered by siRNA/PEG-PEI complexes. Cellular stress responses can induce multiple changes for the cell to better adapt to its environment, including altered protein regulation (Harding et al., 2000) and increased protein removal (Ding et al., 2007). Cell stress does not always appear as cytotoxicity nor is cytotoxicity required to induce cellular protein regulation (Spriggs et al., 2010). As a result, false positive effects are difficult to detect at a dosage showing no apparent cytotoxicity yet inducing cell stress. In fact, even free siRNA considered non-toxic seems to induce cellular stress and display off target effects (Lv et al., 2006; Xue et al., 2014), while little is known if and how PEG-PEI would induce non-specific gene silencing during siRNA transfection without inducing cytotoxicity. Therefore, understanding how PEG-PEI induces false positives is critically important to improve polymer-based siRNA delivery.

Our previous findings suggest that the addition of hydrophobic pendant groups to PNAs would influence intracellular luciferase expression by either directly interacting with cells or indirectly disrupting the protein synthesis process (Rheiner and Bae, 2016; Rheiner et al., 2015). Therefore, this study elucidates the false positive effect of the hydrophobically modified PEG-PEI PNA on siRNA transfection by using PNAs made from combinations of PEG, PEI, poly(L-lysine) (PLL), palmitate (PAL), and deoxycholate (DOC): PEG-PEI (2P),

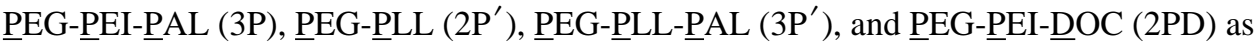
shown in Figure 1. This study focuses on the false positive effect presented by $3 \mathrm{P}$ and determines the influence the PNA's components on the effect by changing aspects of its composition. This included replacement of the long chain, flexible hydrophobic group PAL with a smaller, more rigid hydrophobic group DOC and replacement of the branched PEI 
backbone with a more linear PLL chain. These PNAs (+/- siRNA) are characterized by in vitro siRNA transfection, cell viability, toxicity and immunoblotting in a human colorectal cancer cell line stably overexpressing luciferase (HT29/Luc). Raman spectroscopy is also employed to investigate interactions between hydrophobic pendant groups conjugated to the PNA core and compounds outside the particles. To investigate the cellular stress caused by PNAs, assays determining total protein count, ATP concentration, and cellular membrane porosity are used. Data obtained from these experiments are analyzed to determine the effects of hydrophobic groups and polymer scaffold condensation on false transfection of siRNA/PEG-PEI complexes.

\section{Materials and methods}

\subsection{Chemicals}

PEG (5 kDa, a-methoxy- $\omega$-NHS ester activated) was purchased from NanoCS (New York, NY). Branched PEI (bPEI), deoxycholate (DOC), N-hydroxy succinimide, 4dimethylaminopyridine, 1-ethyl-3-(3-dimethyl aminopropyl) carbodiimide hydrochloride (EDC $\mathrm{HCl})$, palmitoyl chloride, resazurin sodium salt, sulforhodamine $\mathrm{B}$ based in vitro toxicology assay kit (TOX6), and poly(L-lysine) (PLL, 30-70 kDa) were purchased from Sigma Aldrich (St. Louis, MO). RNAiMAX, 4-12\% NuPAGE Bis-Tris precast gels, HEPES buffer ( $\mathrm{pH}$ 8.0, $1 \mathrm{M}$ ), MES buffer (0.1 M, pH 5.0), RIPA buffer, pyridine, NuSieve GTG agarose, dialysis membrane with molecular cut-off (MWCO) of 6-8 and $100 \mathrm{kDa}$, and other organic solvents were purchased from Fisher Scientific (Waltham, MA). siRNA ( $5^{\prime}$ GUUGGCACCAGCAGCGCACUU-3') was purchased from GE Dharmacon (Lafayette, CO). Opti-MEM was purchased from Life Technologies (Carlsbad, CA). Mitochondrial $\mathrm{ToxGlo}^{\mathrm{TM}}$ assay kit and Bradford assay kit were purchased from Promega (Madison, WI). McCoy's 5A, 0.05\% trypsin/EDTA, and phosphate buffered saline (PBS) were from GE Healthcare (Logan, UT). Fetal bovine serum (FBS) was purchased from Atlanta Biologicals (Flowery Branch, GA).

\subsection{Cell culture}

HT29 human colon cancer cell line was purchased from American Type Culture Collection (ATCC, Manassas, VA), and subsequently transfected to establish a cell-line stably expressing firefly luciferase (HT29/Luc). Cells were cultured at logarithmic growth in a humidified environment with $5 \% \mathrm{CO}_{2}$ at $37{ }^{\circ} \mathrm{C}$ in McCoy's 5A media supplemented with $10 \%$ FBS according to ATCC recommendations.

\subsection{Synthesis of PNAs}

PNAs with a PEI backbone (2P and 3P) were synthesized from $25 \mathrm{kDa}$ bPEI, $5 \mathrm{kDa}$ NHSactivated PEG, and palmitoyl chloride as previously reported(Rheiner et al., 2015). In this study, 2P was further modified with DOC through covalent conjugation to the PEI backbone. Briefly, DOC was mixed with NHS, EDC, and DMAP in a 5:5:0.2 molar ratio in MES buffer (0.1 M, pH 5.0). 2P was then added to the mixture in a 1:100 molar ratio of 2P:DOC at room temperature. After 48 hours, the product was purified by dialysis and freeze drying to collect 2PD. 
PNAs with a PLL backbone ( $2 \mathrm{P}^{\prime}$ and $\left.3 \mathrm{P}^{\prime}\right)$ were prepared from 30-70 kDa PLL with $5 \mathrm{kDa}$ NHS-activated PEG and palmitoyl chloride as previously reported(Reichel et al., 2016). 2P' was synthesized by reacting PLL with NHS-activated PEG in water:DMSO:pyridine mixture at ratios of 2:1:1. The solution was mixed for 72 hours at room temperature. $2 \mathrm{P}^{\prime}$ was further modified with palmitoyl chloride to create $3 \mathrm{P}^{\prime} .2 \mathrm{P}^{\prime}$ was dissolved in $\mathrm{THF}$ at $40^{\circ} \mathrm{C}$ and

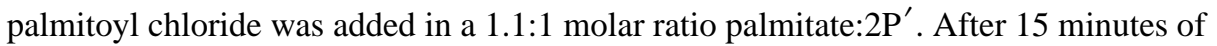
mixing, pyridine in a 2:1 molar ratio of pyridine:palmitate was added as a $\mathrm{HCl}$ scavenger. The solution was reacted for additional 2 hours and purified by ether precipitation and dialysis. The product was collected by freeze drying.

Purity and molecular weight uniformity of PNAs were determined by gel permeation chromatography (GPC, Asahipak GF-7M column, $2 \mathrm{mg} / \mathrm{mL}$, DMF mobile phase, $0.5 \mathrm{~mL} /$ $\min , 40^{\circ} \mathrm{C}$ ). Diameter and surface charge were determined by dynamic light scattering (DLS) and zeta potential measurements using Zetasizer Nano (Malvern, UK).

\subsection{Gel electrophoresis}

PNAs at varying concentrations $(0-1 \mathrm{mg} / \mathrm{mL})$ were mixed with $2 \mu \mathrm{g} / \mathrm{mL}$ siRNA solutions in Opti-MEM at a 1:1 ratio and allowed to equilibrate for 30 minutes. Each mixture $(20 \mu \mathrm{L})$ was then loaded on to a $1 \%$ agarose gel and run at 100 volts for 60 minutes at room temperature in TAE (Tris-Acetate $0.04 \mathrm{M}$, EDTA $0.001 \mathrm{M}$ ) buffer. The gel was stained with $100 \mathrm{ng} / \mathrm{mL}$ ethidium bromide in a TAE buffer and rinsed 3 times with deionized water. The gel was imaged using Typhoon GLA 9500 (GE Healthcare, Logan, UT) fluorescent imager with an ethidium bromide filter set.

\subsection{In vitro siRNA transfection}

Cells were plated at 5,000 cells per well into white opaque 96 well plates and incubated for 24 hours. After 24 hours, PNA solutions were prepared by adding $100 \mu \mathrm{L}$ of $10 \mathrm{mg} / \mathrm{mL}$ PNA solutions in optimem to $100 \mu \mathrm{L}$ of $10 \mu \mathrm{g} / \mathrm{mL}$ siRNA solution or $100 \mu \mathrm{L}$ of Opti-MEM.

Naked siRNA controls were created with $200 \mu \mathrm{L}$ of siRNA solutions at $5 \mu \mathrm{g} / \mathrm{mL}$. Opti-MEM $(200 \mu \mathrm{L})$ was used as the blank control. RNAiMAX controls were created by mixing $5 \mu \mathrm{L}$ of RNAiMAX with $95 \mu \mathrm{L}$ of Opti-MEM and then either $100 \mu \mathrm{L}$ of Opti-MEM or $100 \mu \mathrm{L}$ of 10 $\mu \mathrm{g} / \mathrm{mL}$ siRNA solution for the empty RNAiMAX control or siRNA-loaded RNAiMAX control, respectively. Complexes were formed by incubating the mixtures for 30 minutes at room temperature, except the RNAiMAX control that was incubated for 5 minutes as instructed by the manufacturer. From each well, $20 \mu \mathrm{L}$ of solutions were replaced with their respective complex solutions or controls $(\mathrm{n}=6)$ to yield $1 \mathrm{mg} / \mathrm{mL}$ of PNA and $1 \mu \mathrm{g} / \mathrm{mL}$ siRNA in the well. The plate was incubated for 72 hours at $37^{\circ} \mathrm{C}$ and then read for bioluminescent intensity using GloMax luminometer. The substrate was $100 \mu \mathrm{L}$ of 0.1 $\mathrm{mg} / \mathrm{mL}$ luciferin solution in PBS. Luminescent intensity was collected for 10 seconds and reported as percentage of luciferase activity with respect to control wells. The data was normalized to cell viability (resazurin assay conducted in section 2.6) to account for cell death in the reduction of the luciferase signal. 


\subsection{Cell viability assays}

Four cell viability assays were used in this study to consider different aspects of cell health. Mitochondrial activity was measured by resazurin. Plates used for transfection (see section 2.5) had $10 \mu \mathrm{L}$ of a $1 \mathrm{mM}$ resazurin solution was added to each well and incubated for 3 hours. The plate was read on SpectraMax M5 (Molecular Devices) fluorescent plate reader at excitation/emission of $560 / 590 \mathrm{~nm}$. The readings were subtracted from blank controls and reported as percentage of viable cells.

Sulforhodamine B assay measured total protein concentration in live cells. Cells were seated and dosed with empty 3P based on the method described in section 2.5. After 72 hours post dosage, cells were fixed with $30 \mu \mathrm{L} /$ well of provided TCA solution at $4^{\circ} \mathrm{C}$ for 1 hour. After media removal and air drying, $20 \mu \mathrm{L} /$ well of sulforhodamine B solution was added and allowed to stain for 30 minutes. The stain was then removed, washed with $1 \%$ acetic acid solution, and air dried. Then, $100 \mu \mathrm{L} /$ well of $10 \mathrm{mM}$ Tris base solution was added and incubated for 5 minutes at room temperature. Absorbance was measured at $565 \mathrm{~nm}$ excitation and $690 \mathrm{~nm}$ emission with a SpectraMax M5 (Molecular Devices) fluorescent plate reader. The absorbance at $690 \mathrm{~nm}$ is subtracted from the absorbance at $565 \mathrm{~nm}$ to determine percent viable cells with respect to controls.

Cell membrane integrity and mitochondrial activity of cultured cells were measured with the Mitochondrial ToxGlo assay kit per manufacturer's instruction. HT-29 cells not expressing luciferase were seated and dosed with empty $3 \mathrm{P}$ based on the method described in section 2.5. After 72 hours post dosage, $20 \mu \mathrm{L} /$ well of the provided bis-AAF-R110 solution was added to the wells of the plate and incubated at $37^{\circ} \mathrm{C}$ for 30 minutes. Fluorescence was measured at excitation/emission of 495/520 nm using a SpectraMax M5 (Molecular Devices) fluorescent plate reader. Then, $100 \mu \mathrm{L} /$ well of the provided ATP detection reagent was added to the plate and read for luminescence with GloMax luminometer. The values were compared to their respective controls (untreated wells) and reported as percentages of the control.

\subsection{Western blotting for luciferase expression}

Cells were plated at 50,000 cells/well in a 12 well clear plate. 24 hours later, $200 \mu \mathrm{L}$ of media were replaced with $200 \mu \mathrm{L}$ of Opti-MEM, empty PNAs, or siRNA/PNA complexes. After a 72-hour incubation at $37^{\circ} \mathrm{C}$, cells were lysed with a RIPA buffer and assayed for protein content with a Bradford assay kit (Promega). Then, $100 \mu \mathrm{g}$ of protein for each sample were subjected to electrophoresis through a 4-12\% NuPAGE Bis-Tris precast gel. Afterwards, the proteins were transferred to a nitrocellulose membrane. Primary antibodies used to treat the membranes were anti-luciferase and anti-beta-actin (Cell Signaling Technologies). After washing, the membranes were exposed to IgG-horseradish peroxidase conjugate secondary antibodies for 1 hour and developed with an ECL Western blotting substrate (Promega and SCBT). To detect the slow-migrating firefly luciferase protein in SDS/PAGE, cells were incubated with the $2 \mathrm{P}, 2 \mathrm{P}^{\prime}, 3 \mathrm{P}$, and $3 \mathrm{P}^{\prime}$ for $72 \mathrm{~h}$ as described above, and further incubated in the presence of MG132 $(40 \mu \mathrm{M})$ for $6 \mathrm{~h}$. The protein extracts were run in SDS/PAGE and transferred to PVDF membranes, which were cut above the intact firefly luciferase protein to exclude the intact protein in the membrane, and blotted with the 
rabbit polyclonal anti-firefly luciferase antibody (Promega). The blot was developed with SuperSignal West Femto (Pierce, Thermofisher), and the signals were analyzed in ChemiDoc Imaging Systems (Bio-Rad).

\subsection{PNA-protein and PNA-substrate interaction analyses}

First, $20 \mu \mathrm{L}$ of $10 \mathrm{mg} / \mathrm{mL}$ PNA solutions or RNAiMAX solution were incubated for 10 minutes in wells of a white 96 well plate $(n=6)$. Each well contained $80 \mu \mathrm{L} /$ well of PBS with luciferase proteins to obtain $1 \mathrm{mg} / \mathrm{mL}$ PNA and $5 \mathrm{ng} / \mathrm{mL}$ of luciferase. Then, $100 \mu \mathrm{L}$ of $0.1 \mathrm{mg} / \mathrm{mL}$ luciferin solution in PBS were added to each well and read using GloMax luminometer with an integration time of 10 seconds. Similarly, $2 \mathrm{~mL}$ of $10 \mathrm{mg} / \mathrm{mL}$ PNA solutions or RNAiMAX solution were mixed for 30 minutes with $8 \mathrm{~mL}$ of $0.125 \mathrm{mg} / \mathrm{mL}$ luciferin solution. Then, $100 \mu \mathrm{L}$ of this solution was then injected using GloMax luminometer into each well of a white 96 well plate containing $100 \mu \mathrm{L} /$ well of $5 \mathrm{ng} / \mathrm{mL}$ luciferase in PBS. Luminescence was measured and integrated for 10 seconds. Data is reported as RLU values.

\subsection{Raman spectroscopy}

Raman spectroscopy was conducted in the solid state using a Nicolet iS 50 FTIR with a Raman module (Thermo Fisher Scientific, Waltham, MA). The samples were prepared on a 48 well metal plate with duplicate wells containing either single components (PEG, PAL, or PEI), physical mixtures of components (PEG/PEI, PEG/PAL, PEI/PAL), or complete PNAs (2P or 3P). Duplicate wells allow for one well to contain components or PNAs alone or with siRNA. For analysis of single components, $100 \mu \mathrm{L}$ of a $10 \mathrm{mg} / \mathrm{mL}$ solution of each component and an additional $100 \mu \mathrm{L}$ of water was added to the well. For physical mixtures of components, $100 \mu \mathrm{L}$ of a $10 \mathrm{mg} / \mathrm{ml}$ solution of each component was added to the well combination with an additional $100 \mu \mathrm{L}$ of another component. Then, $1 \mu \mathrm{L}$ of a $1 \mathrm{mg} / \mathrm{mL}$ siRNA solution or $1 \mu \mathrm{L}$ of water was added to respective wells of components or PNAs. The loaded metal plate was stored at room temperature for 30 minutes to allow samples to interact with siRNA. The plate was then transferred to dry ice and the samples were frozen. The frozen samples were then freeze dried overnight and then read on the Raman. Data was collected and deconvoluted using the Omnic Spectra Software suite (Thermo Fisher Scientific, Waltham, Mass.).

\section{Results}

\subsection{PNA synthesis and characterization}

Total five PNAs (2P, 3P, 2PD, 2P' , and $3 \mathrm{P}^{\prime}$ ) were synthesized to investigate the effects of backbone composition (PEI vs. PLL) and hydrophobic groups (PAL vs DOC) on siRNA transfection. Both PEI-based ( $2 \mathrm{P}$ and $3 \mathrm{P})$ and PLL-based $\left(2 \mathrm{P}^{\prime}\right.$ and $\left.3 \mathrm{P}^{\prime}\right)$ PNAs were uniform in size and contained no impurities as confirmed by GPC analysis (Figure $2 \mathrm{~A}$ and B). DLS measurements showed that all PNAs were $30-35 \mathrm{~nm}$ in diameter. Zeta potential measurements had all particles with neutral surface charge. The minimum siRNA complexation ratio (mass of PNA/mass of siRNA) for each particle was determined in Figure $2 \mathrm{C}$ and $\mathrm{D}$. 3P had the largest ratio of $1 \mathrm{mg}$ per $1 \mu \mathrm{g}$ of siRNA. Additionally, 2P showed significantly lower cytotoxicity than naked PEI (Figure 3A) and all particles showed 
negligible toxicity at a concentration of up to $5 \mathrm{mg} / \mathrm{mL}$, except 3P reducing cell viability by $15 \%$ (Figure 3B). To ensure that polymers forming complexes with $1 \mu \mathrm{g} / \mathrm{mL}$ siRNA show no cytotoxicity in in vitro studies, we treated cells with $1 \mathrm{mg} / \mathrm{mL}$ of polymer, which is 5 times lower than concentrations showing any significant reduction in cell viability (Figure $3)$.

\subsection{PNAs inducing reduction of luciferase protein expression}

Approximately $38 \%$ of the HT29 cells stably expressed a firefly luciferase protein (based on fluorescence microscope imagery, not shown), which was sufficient to quantify bioluminescence of cells treated with anti-luciferase siRNA. However, unexpected reductions in luciferase expressions (or false positives in siRNA transfection) were observed in cells dosed with $1 \mathrm{mg} / \mathrm{mL}$ PNAs with and without anti-luciferase siRNA for 72 hours which mimics conditions from the previous study (Rheiner et al., 2015). Figure 4A shows a reduction in luciferase protein of HT29 close to $50 \%$ when treating cells with $3 \mathrm{P}$, and near $40 \%$ when treated with $2 \mathrm{PD}$ regardless of the presence of siRNA. Western blots also show a reduction in cellular luciferase concentration after treatment with 2PD and 3P (Figure 4B). $2 \mathrm{P}$ remains unable to reduce the luciferase expression, which is consistent with previous findings. These results confirm that both PAL and DOC induce false positive effects. Replacing the PNA backbone with PLL from PEI yielded similar results (Figure 5). 2P' was unable to reduce luciferase expression just as $2 \mathrm{P}$. However, $3 \mathrm{P}^{\prime}$ reduced the expression of luciferase by approximately $25 \%$ regardless of the presence of siRNA. Interestingly, $3 \mathrm{P}^{\prime}$ shows a false positive but not to the same extent as 3P.

\subsection{PNA-protein and PNA-substrate interactions}

Although the luciferase assay is a good indicator of protein activity within the cell, it cannot distinguish between proteins that have lost activity and proteins that decrease in number. Previous western blots confirmed a reduction in luciferase protein after incubation with 3P, yet contributions to loss of luciferase activity from interference with PNAs still need to be considered. As shown in Figure 6A, no reduction in luciferase activity was observed when luciferase was incubated with $3 \mathrm{P}$. However, $2 \mathrm{P}$ reduced the activity slightly though this was not observed during the in vitro luciferase assays. When PNAs were incubated with luciferin before adding luciferase neither particle interfered with the luciferase activity (Figure 6B). These results indicate that the PNAs with hydrophobic moieties do not reduce luciferase activity through direct interactions with luciferase or luciferin.

\subsection{Raman spectroscopy}

To better understand how palmitate could interact with other cellular components and induce cell stress, Raman spectroscopy of 2P, 3P, and each of their individual components was conducted (Figure 7). Each polymer was allowed to interact with siRNA and the changes between spectra with and without siRNA were compared. Naked siRNA does not appear on the spectra at the concentration used in this experiment and therefore any changes between spectra can be attributed to vibration changes of the polymers. Vibrational changes are induced either through stabilizations or conformational changes of the chemical bonds in the polymers. A chemical interaction can induce either stabilizations or conformational changes 
and therefore vibrational changes on the Raman spectra indicate some form of interaction between siRNA and the tested polymers.

Based on the Raman spectra, interactions of siRNA with PEG or PAL were minor but the interaction between PEI and siRNA was more pronounced. Physical mixtures of PEI/PAL and PEG/PAL showed unexpected interactions with siRNA. PEG/PAL showed a large change in vibrational intensity although neither component showed significant interaction with siRNA on their own. PEI/PAL increased its vibrational intensity, which indicates that the polymers are more mobile in the presence of siRNA. Raman spectra of 2P and 3P with siRNA slightly changed after the addition of siRNA although the exact influence of PAL in these interactions could not be determined.

\subsection{Evaluation of cell stress caused by $3 P$}

Cytotoxicity assays, Figure 4A, initially showed little toxicity by the PNAs. However, this assay does not account for all factors that affect cell health. Changes in ATP content, total protein amount, and cell membrane porosity were also investigated to determine the presence of cellular stress. Figure 8 shows differences among these cytotoxicity assays. 3P did not have a significant impact on redox activity in the cell but ATP and total protein levels in the cells greatly decreased. Additionally, membrane porosity increased with incubation of $3 \mathrm{P}$.

\subsection{High molecular-weight firefly luciferase formation induced by PNA}

It was considered that luciferase may be increasingly ubiquitinated and degraded in the cell after PNA treatment. Western blotting of cells dosed with PNAs visualized luciferase proteins and their molecular weights. Higher molecular weight luciferase likely corresponds to polyubiquitinated luciferase which is degraded by the proteasome. Western blot analysis of cells dosed for 72 hours with $2 \mathrm{P}, 2 \mathrm{P}^{\prime}, 3 \mathrm{P}$, and $3 \mathrm{P}^{\prime}$ and an additional 6 hours with MG132 proteasome inhibitor confirmed the presence of both normal and high molecular weight luciferase (Figure 9). The proteasome inhibitor prevents the degradation of ubiquitinated luciferase so that it can be visualized on the blot. Figure 9A shows reductions in luciferase concentration, comparable to what is previously seen with $3 \mathrm{P}$ and $3 \mathrm{P}^{\prime}$, and displays little effect by the proteasome inhibitor MG132. Initially high molecular weight luciferase decreased in cells dosed with $3 \mathrm{P}$ and $3 \mathrm{P}^{\prime}$, but these bands increased upon addition of the proteasome inhibitor (Figure 9B) indicating that these bands may be ubiquitinated. All PNAs induced an increase in molecular weight of luciferase while $3 \mathrm{P}$ and $3 \mathrm{P}^{\prime}$ caused the highest increase in this band comparatively. This indicates that $3 \mathrm{P}$ and $3 \mathrm{P}^{\prime}$ increase ubiquitination of luciferase and they may also increase proteasome activity.

\section{Discussion}

We previously investigated PEG-PEI PNAs to improve siRNA delivery by modulating complex stability through addition of palmitate, a hydrophobic moiety (Rheiner et al., 2015). However, we have recently observed an siRNA-independent reduction of luciferase in cells treated with PEG-PEI only after it has been modified with hydrophobic pendant groups (Figure 4), referred to as the false positive effect. Such false positives might be detrimental 
in developing siRNA-based therapeutic options that require specific gene silencing for targeted gene therapy. Additionally, these false positives occur without inducing cytotoxicity that is a common sign of an abnormal cell response. Therefore, this study further investigated potential mechanisms for the unexpected protein reduction by using PNAs made from PEG-PEI with different hydrophobic pendant groups (PAL vs DOC) and polymer backbone (PEI vs PLL).

PNAs with differing hydrophobic moieties may influence the false positive effect differently due structural differences. PNAs with rigid bile acid DOC (2PD) were investigated in addition to PNAs with flexible fatty acid PAL (3P) as these hydrophobic groups are structurally different. It was observed that $2 \mathrm{PD}$ resulted in less luciferase activity relative to 3P. However, it is unknown if this is due to decreased protein activity or cellular concentration of luciferase because the assay does not differentiate between the two conditions. To observe any loss of activity of luciferase due to PNA interaction, PNAs were incubated with free luciferase protein or free luciferin substrate before addition of the other component. Since protein incubation with 3P did not reduce the activity of luciferase, the protein concentration should be lower in the cell and this was supported by western blotting. This determined that the false positive transfection is induced by other hydrophobic moieties and causes a lowered luciferase concentration.

The composition of the cationic backbone is another factor that may alter the false positive effect by changing the PNAs secondary structure formation. The secondary structure of a nanoparticle can influence the location of components within its core by changing how the polymer condenses. PEI, a branched cationic polymer, was replaced by PLL, a more linear cationic polypeptide, the create $2 \mathrm{P}^{\prime}$ and $3 \mathrm{P}^{\prime}$. These particles were similar in size and surface charge to PEI based PNAs. The false positive effect was observed in $3 \mathrm{P}^{\prime}$ but to a lesser extent than 3P. While changing the backbone structure mildly decreased the false positive effect, it did not eliminate it. This indicates that the backbone structure is not as influential as hydrophobic moiety in causing the false positives effect.

Raman spectroscopy offers another method to better understand PALs influence on false positives by examining PAL's influence on PNA interaction. Raman spectroscopy measures the vibrational energy of chemical bonds in a compound which can determine the influence of PNA components on interactions with other compounds (Dootz et al., 2006; Romero et al., 2010; York et al., 2003). These bond vibrations are unique and will change by either shifting their energy spectrum or reducing signal intensity depending on interactions or conformation of PNA components. Raman spectroscopy showed the differences in vibrational energies after the interaction between siRNA and components of 3P, their physical mixtures, and finally the complete PNAs. Initially, the Raman spectra detected minor intensity reductions when siRNA interacted with each separate component of 3P (PEG, PEI, and PAL). However, physical mixtures of components containing PAL (PEI/PAL and PEG/PAL) showed larger vibrational intensity changes than the components. The changes indicated that the PAL had influence over the conformation or interaction of the components with siRNA. When each component is tethered in a PNA, some vibrational changes are more intense when siRNA interacts with the PNAs. Even if the PAL and siRNA are not directly interacting, the Raman spectra show that PAL should influence the Raman 
shifts observed. Therefore, PAL may influence the way 3P condenses around the siRNA, which would further alter the particle conformation and disrupt vibrational energies. While this is not a strong correlation, it gives evidence that the inclusion of PAL in the PNA does influence the PNA condensation when it comes in to contact with other compounds.

PAL influence over PNA interaction with cellular components could induce cell stress without significant cytotoxicity. Cell stress is a condition where cell metabolism, protein concentration, and gene expression may be altered to combat cellular damage or sudden changes in environment (Spriggs et al., 2010). Though cell stress often leads to cytotoxicity, it can still be present without inducing significant toxicity and can be overlooked by some viability assays. The viability assay used in conjunction with the transfection assays was a resazurin based assay which is a widely-used method for determining cell viability in mammalian cells (O'Brien et al., 2000). Resazurin is reduced to a fluorescent molecule, resorufin, in the cell indicating redox activity which correlates with cell viability. This assay focuses on cell metabolism and does not account for other indicators of cell health. Three other markers of cell health were examined to obtain a more complete picture of cell health: total protein concentration in cells, ATP production, and membrane porosity. Cells dosed with 3P exhibited less total protein, lower ATP concentration, and more porous membranes than those of the control group. Lowered total protein production does indicate cell death has occurred but the amount of cell death indicated in Figure 8 would not completely account for the reduced luciferase concentration. More porous membranes and lowered ATP production (Tiwari et al., 2002) are significant signs of cell stress and adds further evidence that $3 \mathrm{P}$ is not completely harmless to the cell. These factors support that $3 \mathrm{P}$ has an adverse effect on the cells that leads to cell stress but the specific cause of the stress is uncertain.

Core components of hydrophobically modified PNAs have been known to cause cell stress in other formulations which may give possible mechanisms to cell stress induced by 3P. Free PAL can cause cell stress and autophagy through endoplasmic reticulum stress (Cunha et al., 2008), free radical formation (Koyama et al., 2011), toll like receptor activation (Suganami et al., 2006), caspase mediated apoptosis (Listenberger et al., 2001), and glucose metabolism reduction (Alcazar et al., 1997). Lipids attached to cationic head groups have been shown to increase enzyme inhibition inside cells, a result of both cationic and lipophilic regions (Aberle et al., 1998). Additionally, cationic polymers and some lipids can reduce protein expression and increased protein degradation due to cell stress (Hollins et al., 2007; Ishii et al., 2015; Omidi et al., 2003; Omidi et al., 2005). However, it should be noted that these cell stress mechanisms are due to free components either alone or removed from their respective nanoparticles. The purification methods used during PNA synthesis removed all free hydrophobic groups and the hydrophobic moieties to the PEI backbone are stable so that no free hydrophobic groups would be present in formulation. However, the chemically conjugated hydrophobic moieties may be able to interact with cellular components in a similar way to these free hydrophobic groups. Although these formulations differ from PNAs, they present possible mechanisms by which hydrophobic moieties can cause cellular stress through interaction with the cell.

3P induced cell stress may produce false positives by causing fluctuation of cellular protein concentration, including luciferase. One mechanism of protein reduction in the cell is 
increased ubiquitination of proteins, which increases their proteasome degradation. Protein ubiquitination occurs normally in the cell as part of the ubiquitination-proteasome pathway but is increased in times of stress or when certain pathways are activated, such as autophagy (Kirkin et al., 2009). Western blotting confirmed an increase in the molecular weight of luciferase inside cells dosed with hydrophobically modified PNAs. Although this is not direct evidence of luciferase ubiquitination, an increase in molecular weight of a protein can often be the result of ubiquitination. The increase in the high molecular weight luciferase band after proteasome inhibition gives further evidence that this is ubiquitinated luciferase. As previously mentioned, hydrophobic groups may cause oxidative and endoplasmic reticulum stress which has been shown to increase protein ubiquitination (Shang and Taylor, 2011; Yoshida, 2007). These stresses can also lead to regulated cell death which would increase protein ubiquitination (Orlowski, 1999) as well. We emphasize that this process is one plausible mechanism leading to false positive effects shown in our study and there might be a more complicated interplay among toxicity, cell stress, and nanoparticle compositions. Although the exact cellular mechanism causing increased ubiquitination is unknown, this gives a better understanding of the interactions hydrophobically modified PNAs are inducing in the cell.

Based on the results of this study, we propose that the hydrophobically modified PNAs can interact with cellular components by allowing hydrophobic groups to influence PNA interactions with compounds outside of the nanoparticle. The data suggests that the hydrophobic group is most influential, compared with backbone structure, in generating the false positive. To achieve this, the hydrophobic component would be required to interact near the surface of the PNA. PNAs exist as a single polymer, core/shell systems regardless of the presence of siRNA, as evidenced by our previous study (Rheiner and Bae, 2016), and empty PNAs should behave similarly to complexed PNAs. Hydrophobic moieties are housed in the core of the PNA and the PEG shell should prevent their interaction while the PNA maintains its secondary structure, or folded state. However, PNAs could be in a state of equilibrium between the folded and unfolded states. The addition of PEG and PAL will drive the equilibrium toward the folded state, forming a core/shell environment, but a small percentage of the unfolded state will persist. This unfolded state may allow the PAL to interact with cellular components, possibly causing endoplasmic reticulum stress.

While this mechanism accounts for interactions outside the PNA, the PNA may additionally interact with cellular components reaching its core. PNAs may also capture molecules needed for cellular metabolism, such as ATP or other important cellular process cofactors, which are small enough to enter the particle core. Entrapping these important cellular molecules would have induced cellular stress causing non-specific reduction in luciferase. In particular, 3P has both cationic and hydrophobic regions, and thus they can attract coenzymes like ATP through both ionic and hydrophobic interactions. After the coenzyme is charge neutralized, they may be entrapped in PNAs further strongly by hydrophobic interactions. We previously confirmed that PNAs altered drug release patterns in the presence of hydrophobic excipients outside of the PNAs, yet these hydrophobic excipients were not found to enter the PNA but weakly bound the surface of the PNA (Reichel and Bae, 2016). Therefore, binding of cofactors to the surface or inside the PNA is possible and can 
cause cell stress. Further investigation into these mechanisms is ongoing and will be reported in future studies.

\section{Conclusions}

This study confirmed the false positive siRNA transfection in the luciferase reporter assay, induced by siRNA/PEG-PEI complexes modified with hydrophobic pendant groups. The false positive effect was not limited to a specific hydrophobic moiety, but could be triggered by many other factors such as cationic polymer composition, conformation, and complex stability. Changes in core condensation based on backbone linearity reduce the false positive effect but are unable to eliminate it. The hydrophobic moiety appeared to cause cellular stress leading to over ubiquitination and degradation of luciferase. The exact cellular mechanism by which the effect is induced remains elusive but these results clearly demonstrate that hydrophobic core components of PEG-PEI based siRNA delivery vehicles can induce false positive siRNA transfection in luciferase reporter assays. These findings provide a valuable insight into designing non-viral gene vectors made from PEG-PEI and potentially other types of cationic polymers.

\section{Acknowledgments}

The authors acknowledge the financial support from the University of Kentucky Cancer Nanotechnology Training Center (UK CNTC), funded by the NCI/NIH and part of the National Cancer Institute Alliance. This work is partially supported by the University of Kentucky Markey Cancer Center pilot grant. Derek Reichel acknowledges financial support from the University of Kentucky GSAY fellowship.

Funding: This work was supported by the University of Kentucky Cancer Nanotechnology Training Center (UK CNTC), funded by the NCI/NIH and part of the National Cancer Institute Alliance. This work was also supported by the University of Kentucky Markey Cancer Center pilot grant.

\section{References}

Aberle AM, Tablin F, Zhu J, Walker NJ, Gruenert DC, Nantz MH. A novel tetraester construct that reduces cationic lipid-associated cytotoxicity. Implications for the onset of cytotoxicity. Biochemistry. 1998; 37:6533-6540. [PubMed: 9572871]

Alcazar O, Qiu-yue Z, Gine E, Tamarit-Rodriguez J. Stimulation of islet protein kinase C translocation by palmitate requires metabolism of the fatty acid. Diabetes. 1997; 46:1153-1158. [PubMed: 9200650]

Auld DS, Thorne N, Nguyen DT, Inglese J. A specific mechanism for nonspecific activation in reporter-gene assays. ACS Chem Biol. 2008; 3:463-470. [PubMed: 18590332]

Bartlett DW, Davis ME. Insights into the kinetics of siRNA-mediated gene silencing from live-cell and live-animal bioluminescent imaging. Nucleic acids research. 2006; 34:322-333. [PubMed: 16410612]

Choy G, O'Connor S, Diehn FE, Costouros N, Alexander HR, Choyke P, Libutti SK. Comparison of noninvasive fluorescent and bioluminescent small animal optical imaging. BioTechniques. 2003; 35:1022-1026. 1028-1030. [PubMed: 14628676]

Cunha DA, Hekerman P, Ladrière L, Bazarra-Castro A, Ortis F, Wakeham MC, Moore F, Rasschaert J, Cardozo AK, Bellomo E, Overbergh L, Mathieu C, Lupi R, Hai T, Herchuelz A, Marchetti P, Rutter GA, Eizirik DL, Cnop M. Initiation and execution of lipotoxic ER stress in pancreatic $\beta$ - cells. Journal of Cell Science. 2008; 121:2308. [PubMed: 18559892]

Davis ME, Zuckerman JE, Choi CH, Seligson D, Tolcher A, Alabi CA, Yen Y, Heidel JD, Ribas A. Evidence of RNAi in humans from systemically administered siRNA via targeted nanoparticles. Nature. 2010; 464:1067-1070. [PubMed: 20305636] 
Ding WX, Ni HM, Gao W, Yoshimori T, Stolz DB, Ron D, Yin XM. Linking of autophagy to ubiquitin-proteasome system is important for the regulation of endoplasmic reticulum stress and cell viability. Am J Pathol. 2007; 171:513-524. [PubMed: 17620365]

Dootz R, Nie J, Du B, Herminghaus S, Pfohl T. Raman and surface enhanced Raman microscopy of microstructured polyethylenimine/DNA multilayers. Langmuir. 2006; 22:1735-1741. [PubMed: 16460099]

Fella C, Walker GF, Ogris M, Wagner E. Amine-reactive pyridylhydrazone-based PEG reagents for pH-reversible PEI polyplex shielding. European journal of pharmaceutical sciences : official journal of the European Federation for Pharmaceutical Sciences. 2008; 34:309-320. [PubMed: 18586470]

Harding HP, Novoa I, Zhang Y, Zeng H, Wek R, Schapira M, Ron D. Regulated translation initiation controls stress-induced gene expression in mammalian cells. Mol Cell. 2000; 6:1099-1108. [PubMed: 11106749]

Helmfors H, Eriksson J, Langel U. Optimized luciferase assay for cell-penetrating peptide-mediated delivery of short oligonucleotides. Anal Biochem. 2015; 484:136-142. [PubMed: 26049099]

Hollins AJ, Omidi Y, Benter IF, Akhtar S. Toxicogenomics of drug delivery systems: Exploiting delivery system-induced changes in target gene expression to enhance siRNA activity. J Drug Target. 2007; 15:83-88. [PubMed: 17365277]

Ishii M, Maeda A, Tani S, Akagawa M. Palmitate induces insulin resistance in human HepG2 hepatocytes by enhancing ubiquitination and proteasomal degradation of key insulin signaling molecules. Arch Biochem Biophys. 2015; 566:26-35. [PubMed: 25527164]

Kim DH, Rossi JJ. Strategies for silencing human disease using RNA interference. Nat Rev Genet. 2007; 8:173-184. [PubMed: 17304245]

Kirkin V, McEwan DG, Novak I, Dikic I. A role for ubiquitin in selective autophagy. Mol Cell. 2009; 34:259-269. [PubMed: 19450525]

Koyama T, Kume S, Koya D, Araki Si, Isshiki K, Chin-Kanasaki M, Sugimoto T, Haneda M, Sugaya T, Kashiwagi A, Maegawa H, Uzu T. SIRT3 attenuates palmitate-induced ROS production and inflammation in proximal tubular cells. Free Radical Biology and Medicine. 2011; 51:1258-1267. [PubMed: 21664458]

Lee SJ, Kim MJ, Kwon IC, Roberts TM. Delivery strategies and potential targets for siRNA in major cancer types. Adv Drug Deliv Rev. 2016; 104:2-15. [PubMed: 27259398]

Listenberger LL, Ory DS, Schaffer JE. Palmitate-induced apoptosis can occur through a ceramideindependent pathway. J Biol Chem. 2001; 276:14890-14895. [PubMed: 11278654]

Liu Y, Liu Z, Wang Y, Liang YR, Wen X, Hu J, Yang X, Liu J, Xiao S, Cheng D. Investigation of the performance of PEG-PEI/ROCK-II-siRNA complexes for Alzheimer's disease in vitro. Brain Res. 2013; 1490:43-51. [PubMed: 23103413]

Lv H, Zhang S, Wang B, Cui S, Yan J. Toxicity of cationic lipids and cationic polymers in gene delivery. Journal of controlled release : official journal of the Controlled Release Society. 2006; 114:100-109. [PubMed: 16831482]

Malek A, Czubayko F, Aigner A. PEG grafting of polyethylenimine (PEI) exerts different effects on DNA transfection and siRNA-induced gene targeting efficacy. J Drug Target. 2008; 16:124-139. [PubMed: 18274933]

Nelson CE, Kintzing JR, Hanna A, Shannon JM, Gupta MK, Duvall CL, Al NET. Balancing cationic and hydrophobic content of PEGylated siRNA polyplexes enhances endosome escape, stability, blood circulation time, and bioactivity in vivo. ACS nano. 2013; 7:8870-8880. [PubMed: 24041122]

O'Brien J, Wilson I, Orton T, Pognan F. Investigation of the Alamar Blue (resazurin) fluorescent dye for the assessment of mammalian cell cytotoxicity. European Journal of Biochemistry. 2000; 267:5421-5426. [PubMed: 10951200]

Omidi Y, Hollins AJ, Benboubetra M, Drayton R, Benter IF, Akhtar S. Toxicogenomics of non-viral vectors for gene therapy: a microarray study of lipofectin- and oligofectamine-induced gene expression changes in human epithelial cells. J Drug Target. 2003; 11:311-323. [PubMed: 14668052] 
Omidi Y, Hollins AJ, Drayton RM, Akhtar S. Polypropylenimine dendrimer-induced gene expression changes: the effect of complexation with DNA, dendrimer generation and cell type. J Drug Target. 2005; 13:431-443. [PubMed: 16308212]

Orlowski RZ. The role of the ubiquitin-proteasome pathway in apoptosis. Cell Death Differ. 1999; 6:303-313. [PubMed: 10381632]

Pandey AP, Sawant KK. Polyethylenimine: A versatile, multifunctional non-viral vector for nucleic acid delivery. Mater Sci Eng C Mater Biol Appl. 2016; 68:904-918. [PubMed: 27524093]

Patil Y, Panyam J. Polymeric nanoparticles for siRNA delivery and gene silencing. International journal of pharmaceutics. 2009; 367:195-203. [PubMed: 18940242]

Reichel D, Bae Y. Comparison of Dialysis- and Solvatofluorochromism-Based Methods to Determine Drug Release Rates from Polymer Nanoassemblies. Pharmaceutical Research. 2016:1-14.

Reichel D, Lee MJ, Lee W, Kim KB, Bae Y. Tethered polymer nanoassemblies for sustained carfilzomib release and prolonged suppression of proteasome activity. Ther Deliv. 2016; 7:665681. [PubMed: 27790952]

Rheiner S, Bae Y. Increased poly(ethylene glycol) density decreases transfection efficacy of siRNA/ poly(ethylene imine) complexes. AIMS Bioengineering. 2016; 3:454-467.

Rheiner S, Rychahou P, Bae Y. Effects of the Lipophilic Core of Polymer Nanoassemblies on Intracellular Delivery and Transfection of siRNA. AIMS Biophysics. 2015; 2:284-302.

Romero G, Estrela-Lopis I, Zhou J, Rojas E, Franco A, Espinel CS, Fernández AG, Gao C, Donath E, Moya SE. Surface Engineered Poly(lactide-co-glycolide) Nanoparticles for Intracellular Delivery: Uptake and Cytotoxicity-A Confocal Raman Microscopic Study. Biomacromolecules. 2010; 11:2993-2999. [PubMed: 20882998]

Shang F, Taylor A. Ubiquitin-proteasome pathway and cellular responses to oxidative stress. Free Radic Biol Med. 2011; 51:5-16. [PubMed: 21530648]

Spriggs KA, Bushell M, Willis AE. Translational regulation of gene expression during conditions of cell stress. Mol Cell. 2010; 40:228-237. [PubMed: 20965418]

Suganami T, Tanimoto-Koyama K, Nishida J, Itoh M, Yuan X, Mizuarai S, Kotani H, Yamaoka S, Miyake K, Aoe S, Kamei Y, Ogawa Y. Role of the Toll-like Receptor 4/NF- $\kappa$ B Pathway in Saturated Fatty Acid-Induced Inflammatory Changes in the Interaction Between Adipocytes and Macrophages. Arteriosclerosis, Thrombosis, and Vascular Biology. 2006; $27: 84$.

Thorne N, Inglese J, Auld DS. Illuminating insights into firefly luciferase and other bioluminescent reporters used in chemical biology. Chem Biol. 2010; 17:646-657. [PubMed: 20609414]

Tiwari BS, Belenghi B, Levine A. Oxidative stress increased respiration and generation of reactive oxygen species, resulting in ATP depletion, opening of mitochondrial permeability transition, and programmed cell death. Plant Physiol. 2002; 128:1271-1281. [PubMed: 11950976]

Wightman L, Kircheis R, Rössler V, Carotta S, Ruzicka R, Kursa M, Wagner E. Different behavior of branched and linear polyethylenimine for gene delivery in vitro and in vivo. The journal of gene medicine. 2001; 3:362-372. [PubMed: 11529666]

Wittrup A, Lieberman J. Knocking down disease: a progress report on siRNA therapeutics. Nat Rev Genet. 2015; 16:543-552. [PubMed: 26281785]

Xue HY, Liu S, Wong HL. Nanotoxicity: a key obstacle to clinical translation of siRNA-based nanomedicine. Nanomedicine (Lond). 2014; 9:295-312. [PubMed: 24552562]

York SS, Boesch SE, Wheeler RA, Frech R. Vibrational Assignments for High Molecular Weight Linear Polyethylenimine (LPEI) Based on Monomeric and Tetrameric Model Compounds. Macromolecules. 2003; 36:7348-7351.

Yoshida H. ER stress and diseases. FEBS J. 2007; 274:630-658. [PubMed: 17288551]

Zintchenko A, Philipp A, Dehshahri A, Wagner E. Simple modifications of branched PEI lead to highly efficient siRNA carriers with low toxicity. Bioconjugate chemistry. 2008; 19:1448-1455. [PubMed: 18553894]

\section{Abbreviations}

PEI Polyethylenimine 


$\begin{array}{ll}\text { PLL } & \text { Poly-L-Lysine } \\ \text { PEG } & \text { Poly(ethylene glycol) } \\ \text { PAL } & \text { Palmitate } \\ \text { DOC } & \text { Deoxycholic Acid } \\ \text { 2P } & \text { PEG-PEI } \\ \text { 2P' } & \text { PEG-PLL } \\ \text { 2PD } & \text { PEG-PEI-DOC } \\ \text { 3P } & \text { PEG-PEI-PAL } \\ \text { 3P' } & \text { PEG-PLL-PAL }\end{array}$




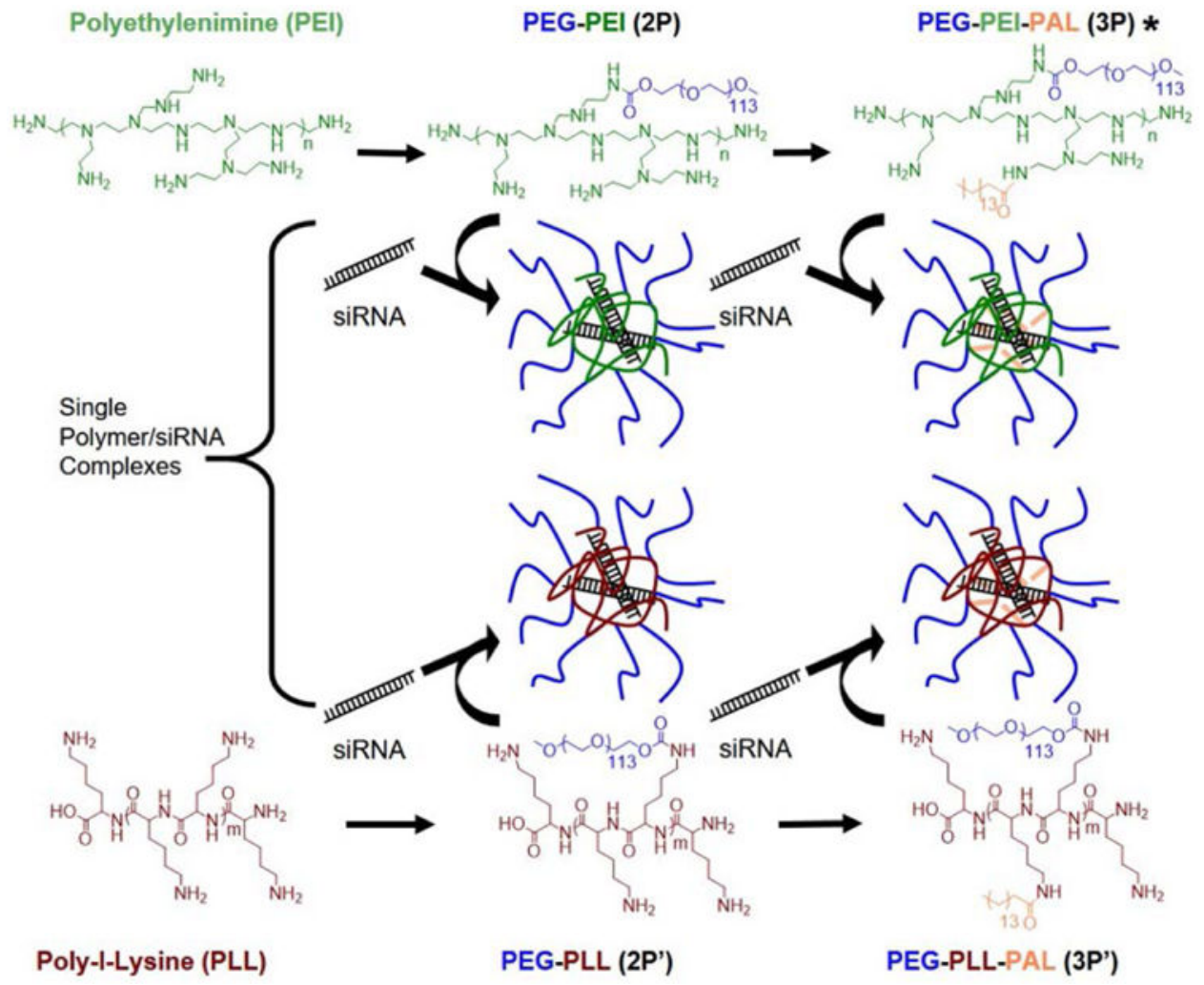

Figure 1. PNA scheme

Progression of PNA development from backbone polymer (PEI or PLL) to subsequent random covalent modification with PEG and hydrophobic moiety (DOC or PAL) and finally their complexes with siRNA. *: Palmitate was replaced with deoxycholic acid (DOC) to generate PEG-PEI-DOC (2PD). 
A. PEI Based PNAs
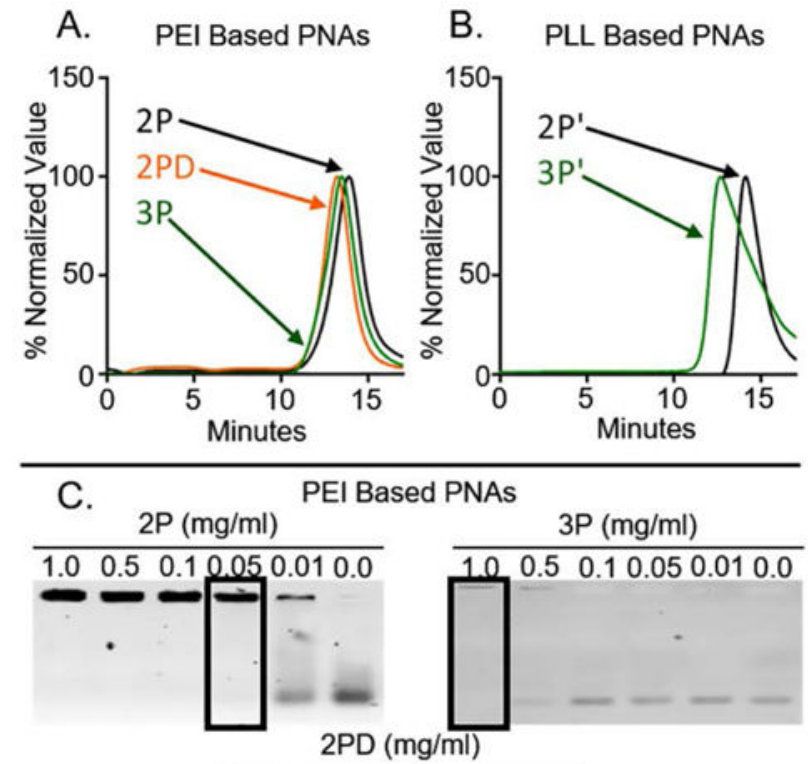

1.00 .5010 .050 .010 .0
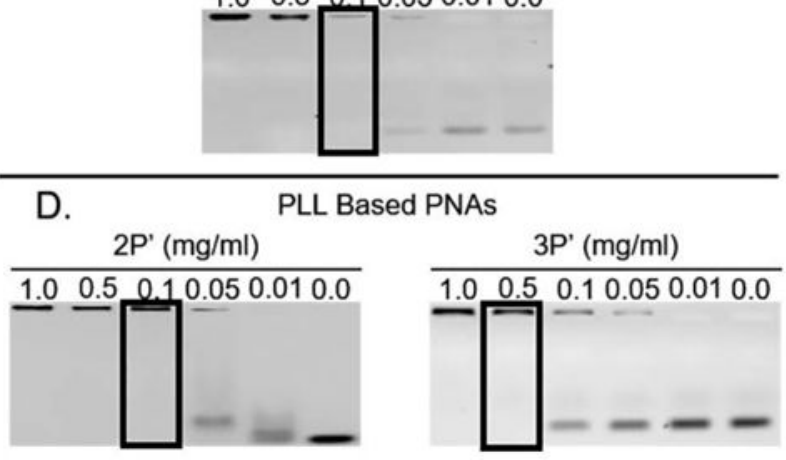

Figure 2. Characterization of PNAs

Gel permeation chromatography (GPC) spectra shows particle uniformity and purity of PEI

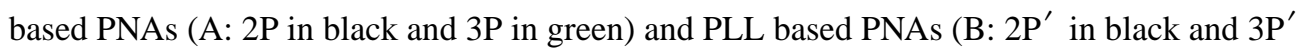
in green). Gel electrophoresis was run for PEI based PNA/siRNA mixtures (C) and PLL based PNA/siRNA mixtures (D) with $72 \mathrm{nM}$ siRNA and varying concentrations of PNA. Bands retained in the well indicate complexes have been formed and the lowest amount of polymer needed to form complexes with siRNA is indicated by a black box. 

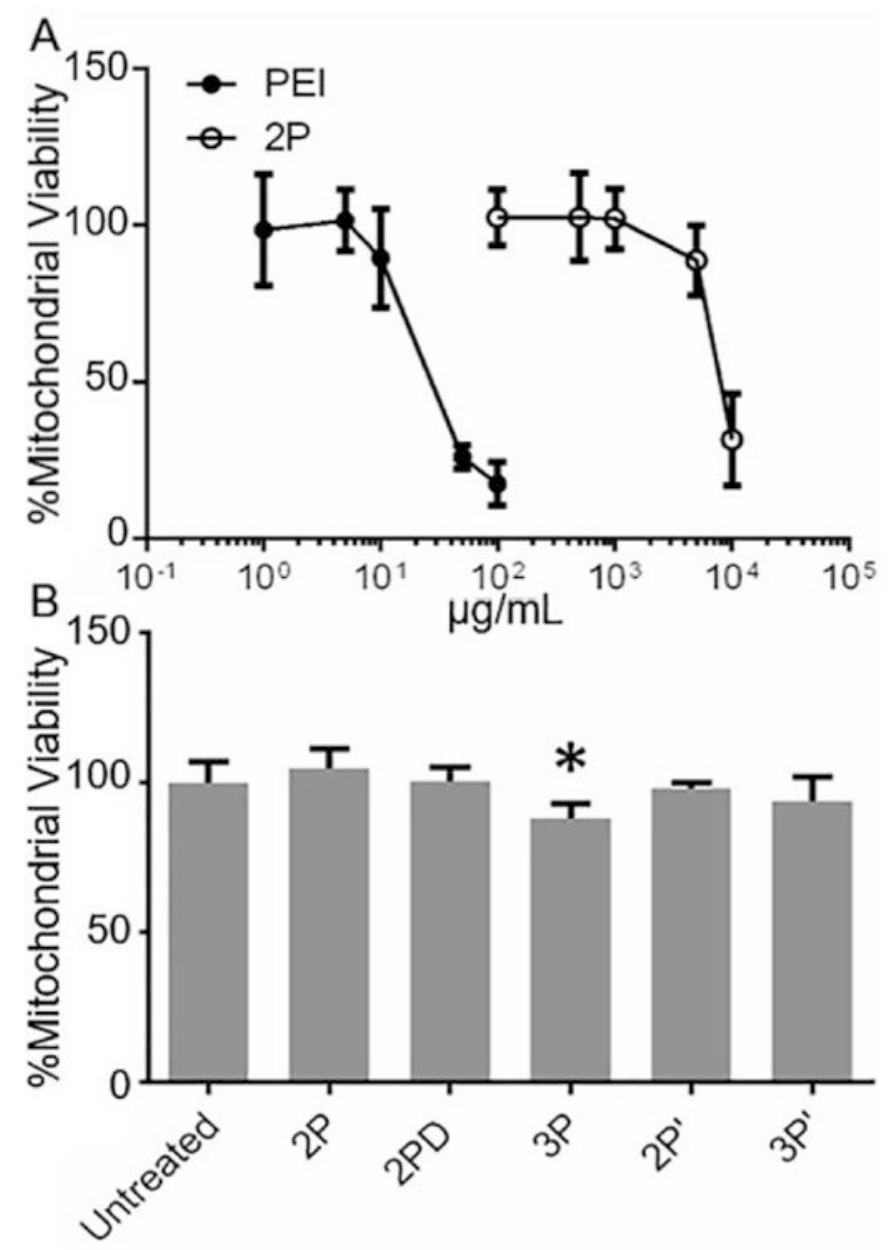

Figure 3. Toxicity of TNAs at a high concentration

A: Viability versus concentration curves of naked PEI (closed circle) and 2P (open circle) after 72-hour incubation. B: Resazurin viability assay of empty TNAs at $5 \mathrm{mg} / \mathrm{mL}$ after 72hour incubation. * represents significant difference from the untreated control condition $(\mathrm{p}<0.01)$. 


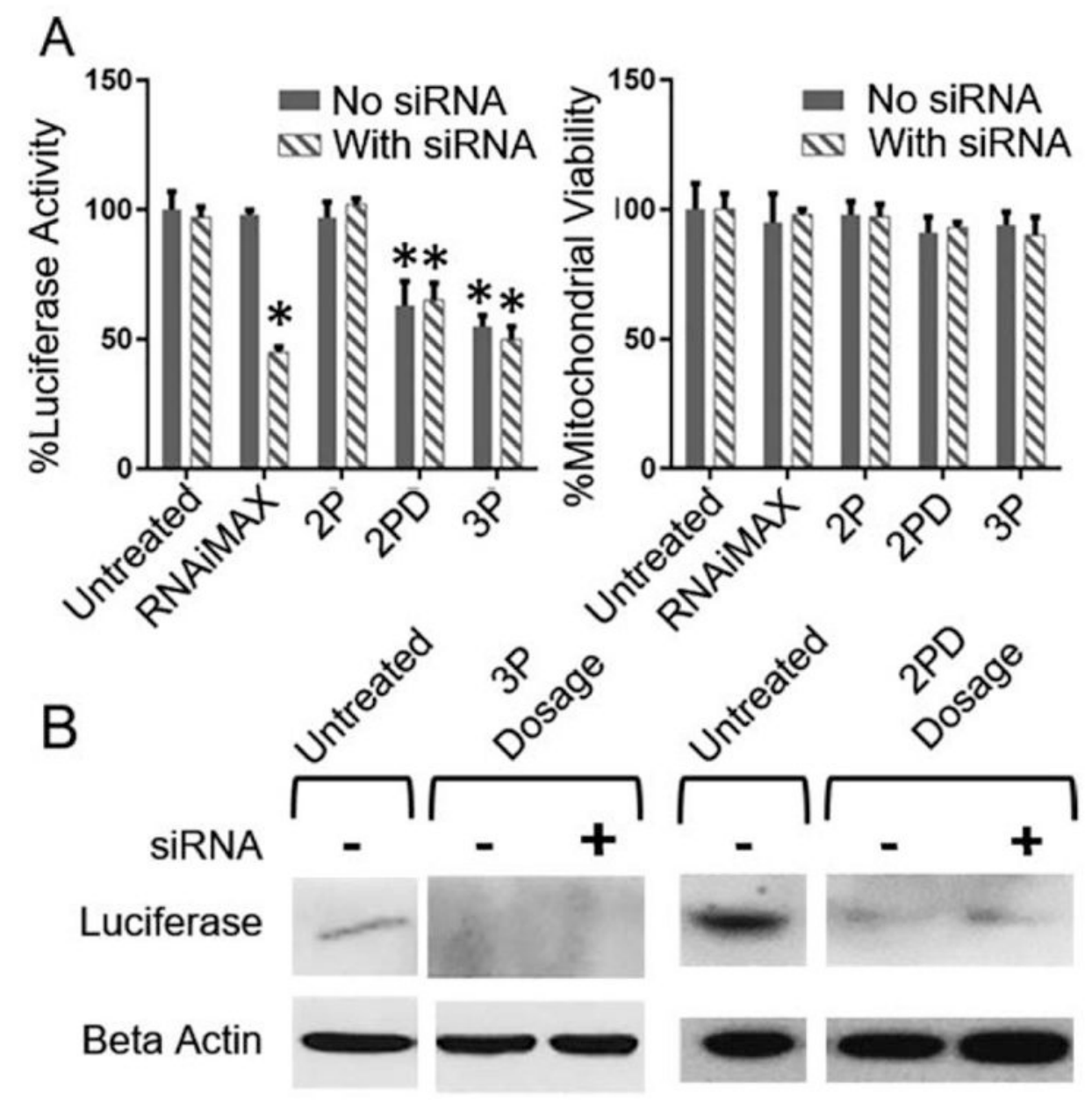

Figure 4. PNA in vitro luciferase reduction

A: Luminometric assay of luciferase (left) and mitochondrial activity based viability assay (right) after 72-hour incubation with each particle. Solid bars represent each condition without siRNA and striped bars represent condition with $1 \mu \mathrm{g} / \mathrm{mL}$ anti-luciferase siRNA. B: Western blotting results after 72-hour incubation with loaded and unloaded 3P and 2PD including an untreated control. * represents significant difference from the untreated control condition $(\mathrm{p}<0.01)$. 


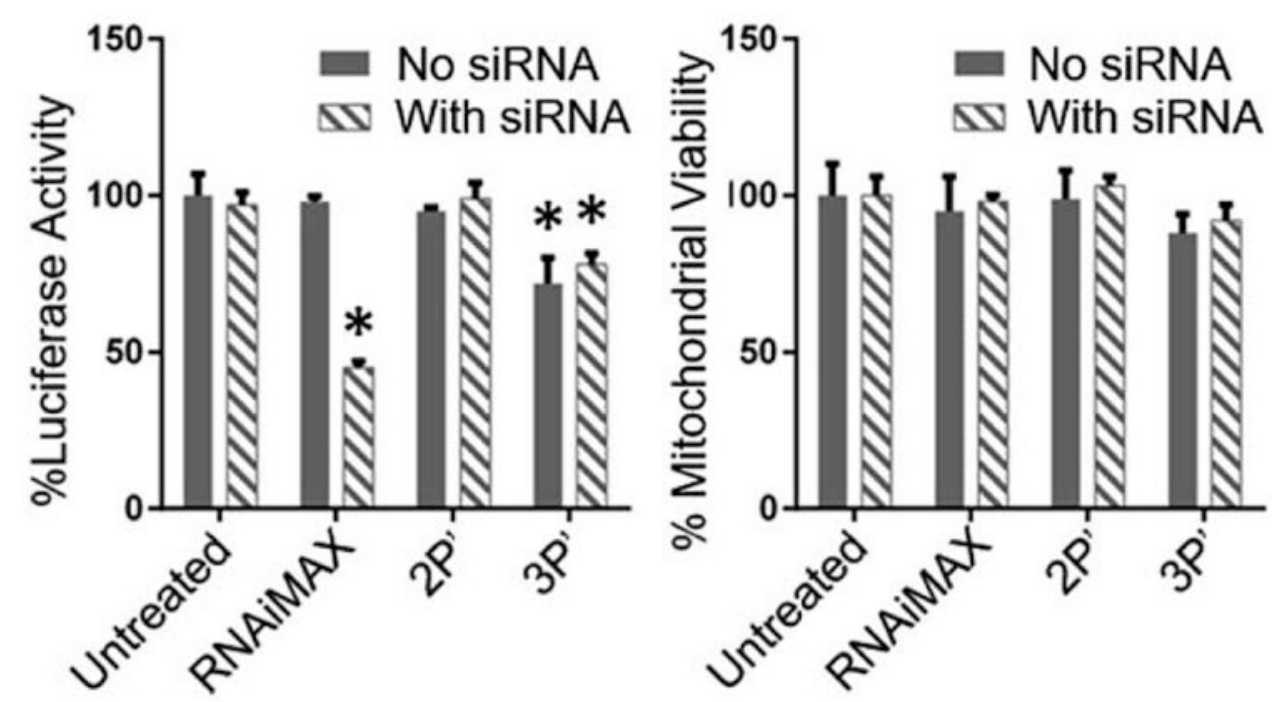

Figure 5. PLL Based PNA in vitro luciferase reduction

luminometric assay of luciferase (left) and mitochondrial activity viability assay (right) after 72-hour incubation with each particle at a concentration of $1 \mathrm{mg} / \mathrm{mL}$. Grey bars represent each condition without siRNA and striped bars represent condition with anti-luciferase 1 $\mu \mathrm{g} / \mathrm{mL}$ siRNA. * represents significant difference from the untreated control condition $(\mathrm{p}<0.01)$. 


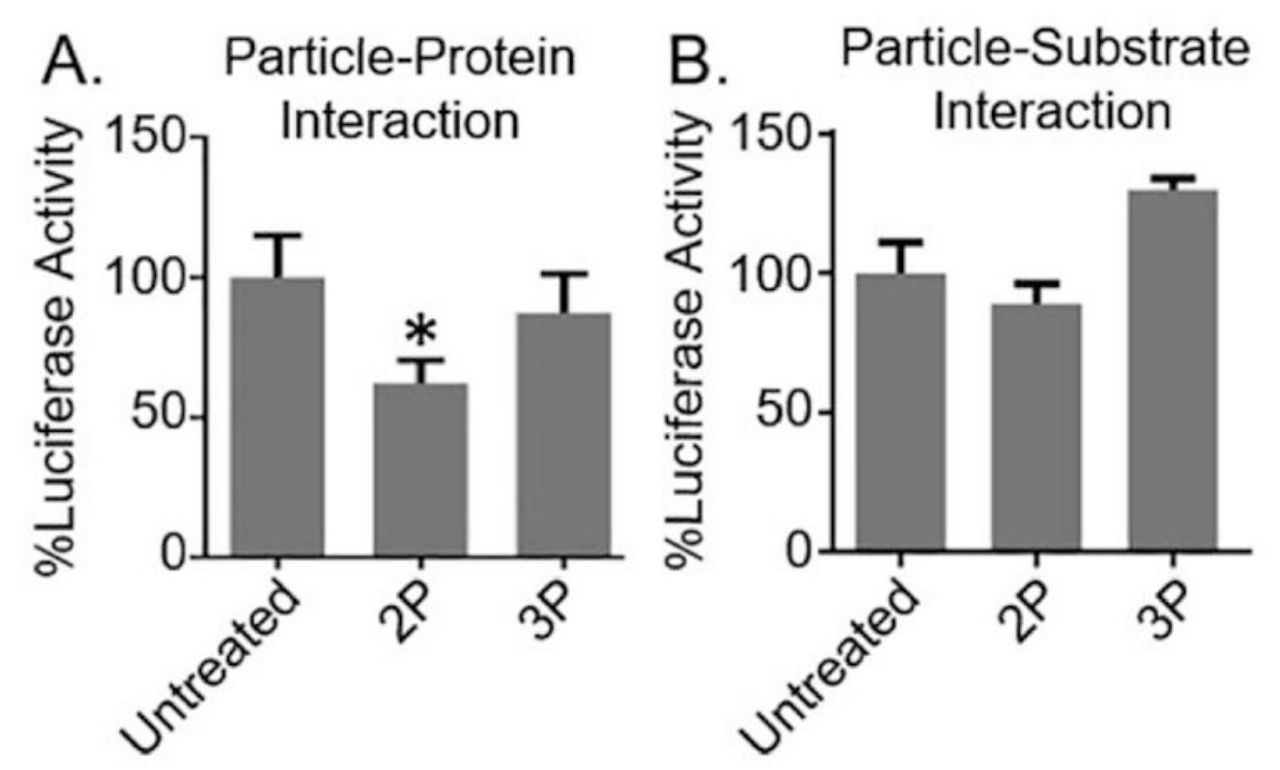

Figure 6. Direct PNA/protein and PNA/substrate interactions

A: Interaction between PNAs and Luciferase protein was observed by incubating the protein and PNA together for 10 minutes. Then luciferin solution was added to the well and a luminescence reading was taken. The readings were normalized to the control well of luciferase protein alone. B: PNA and Luciferin (substrate to luciferase) direct interaction was observed by 30-minute incubation of PNA and Luciferin before an injection of luciferase solution was added to the well. A luminescence reading was taken and the values normalized to the control well which did not contain PNAs. * represents significant difference from the untreated control condition $(\mathrm{p}<0.01)$. 

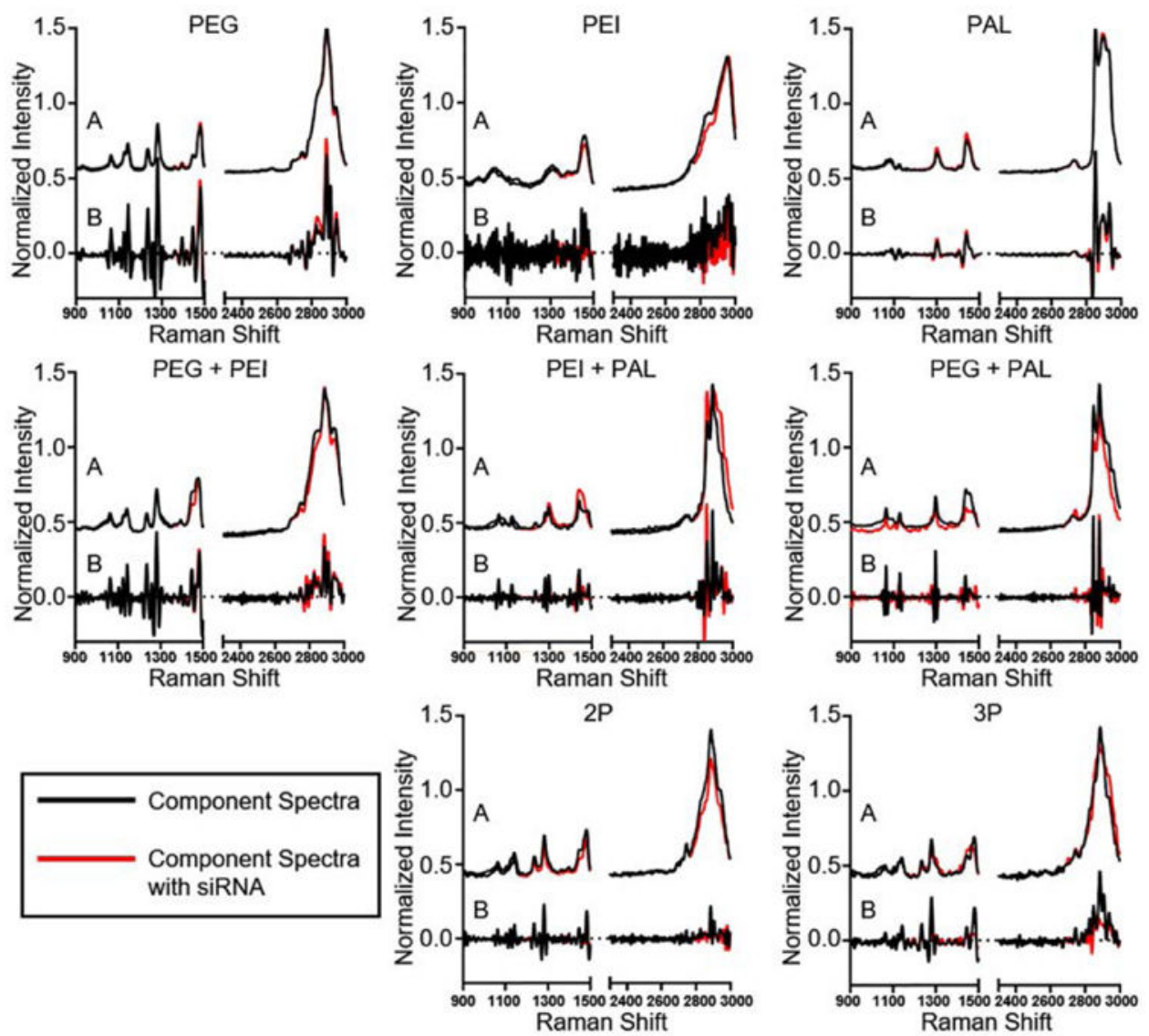

Figure 7. Raman spectroscopy of PNAs and their components

Raman spectrographs of each component of PNAs (top row), binary physical mixture of PNA components (middle row), and chemically conjugated PNAs (bottom row).

Spectrograph A is the raw form of the Raman shift and spectrograph B is the deconvoluted raw spectra. Red lines indicate components or PNAs mixed with siRNA and black lines indicate components or PNAs alone. 


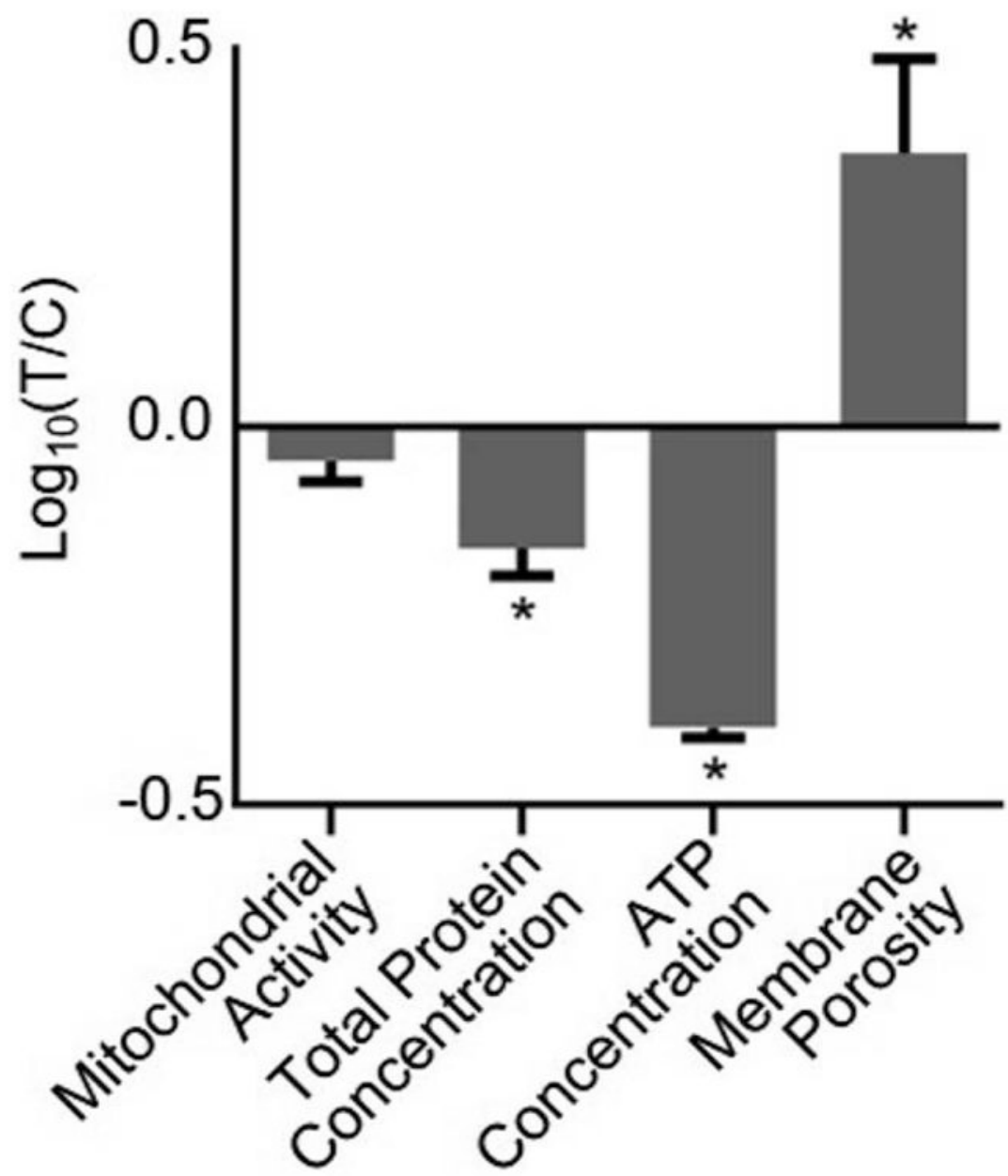

Figure 8. Alternative cell health markers after incubation with 3P

Four cell viability markers were examined to elucidate cell stress occurring within cells after 72-hour incubation with empty $3 \mathrm{P}$ complexes at $1 \mathrm{mg} / \mathrm{mL}$. Mitochondrial activity was analyzed using the resazurin assay, total protein count was determined using the Sulforhodamine B assay, total ATP count was done using a luminometric assay in HT29 cells that did not express luciferase, and membrane porosity was analyzed by an assay that measured the cells ability to reduce Bis-AAF-R110 which can only be reduced from inside the cell. Values were plotted as the log of the ratio between the cells dosed with 3P and the control cells. Values statistically different from their control condition are denoted by * $(\mathrm{p}<0.01)$. 

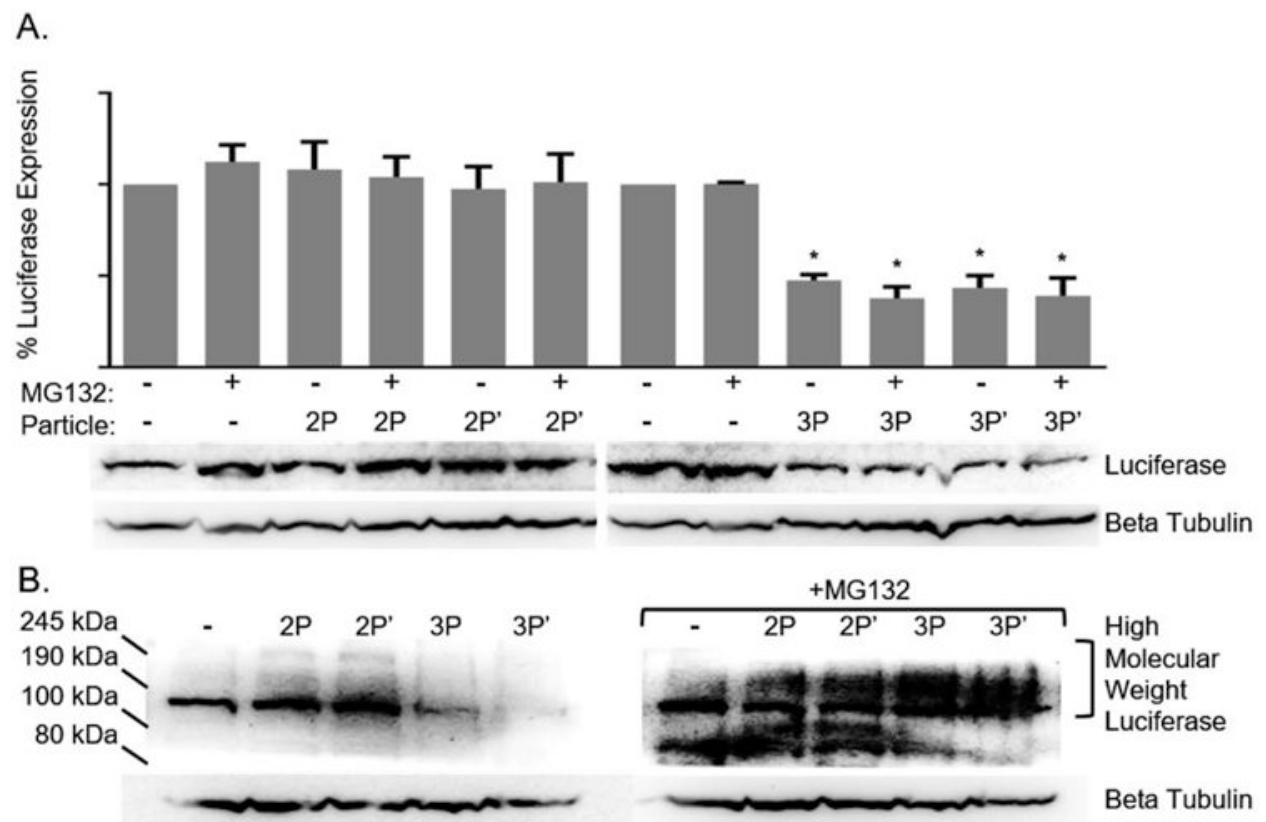

Figure 9. PNA induced ubiquitination of luciferase

Western blots detailed the expression of (A) luciferase, and (B) high molecular weight luciferase after $72 \mathrm{~h}$ dosage of PNAs in HT-29-luc cells. Additionally, cells were dosed as indicated with MG132 proteasome inhibitor for $6 \mathrm{~h}$ before cell lysis. Cellular expression of luciferase was compared with beta tubulin. * denotes that the column is significantly different from the no particle, no MG132 condition $(\mathrm{p}<0.01)$. 